\title{
Review
}

Pathobiology

Pathobiology 2009;76:90-97

DOI: $10.1159 / 000201677$

\section{Trends in Hormone Therapy and Breast Cancer Incidence - Results from the German Network of Cancer Registries}

\author{
Alexander Katalinic ${ }^{\mathrm{a}, \mathrm{b}}$ Anna Lemmer ${ }^{\mathrm{a}} \quad$ Anette Zawinell $^{\mathrm{c}}$ Rajesh Rawal $^{\mathrm{a}}$ \\ Annika Waldmann ${ }^{\mathrm{a}}$ \\ anstitute for Cancer Epidemiology, University of Lübeck, and ${ }^{b}$ Association of Population-Based Cancer Registries \\ in Germany, Lübeck, and ' AOK Research Institute, Bonn, Germany
}

\section{Key Words}

Breast cancer incidence $\cdot$ German Network of Cancer Registries $\cdot$ Hormone therapy $\cdot$ Menopause $\cdot$ Risk factors for breast cancer

\begin{abstract}
Objective: Menopausal hormone therapy $(\mathrm{HT})$ is a proven risk factor for breast cancer. Recent reports presented declining trends in breast cancer incidence, which were attributed to parallel declining trends in HT. Therefore, we analyzed recent data on hormone therapy and breast cancer incidence in Germany. Methods: We performed a population-based survey using breast cancer incidence (from cancer registries) and hormone prescription data (from health insurances) for the time period from 1997 to 2006. Age-standardized rates were calculated and joinpoint regression analyses for trends were performed. Results: Prescription of HT started to decline in 1999; about 2 years later, a parallel decline in breast cancer incidence was observed. HT prescription decreased by $69 \%$ up to 2006 , and breast cancer incidence by $6.8 \%$ for all age groups (2002-2005) and $12.8 \%$ in the age group from 50 to 69 years. The reductions in HT prescription and breast cancer incidence were markedly correlated across the federal states in Germany. Conclusion: The recent decline in breast cancer incidence following de-
\end{abstract}

creasing $\mathrm{HT}$ prescription suggests a causal relationship between the risk of breast cancer and HT in Germany. Even after the 'big HT drop' in Germany, significant differences in HT prescription as well as breast cancer incidence persist at the federal state level. These results should be discussed in a public health context.

Copyright $\odot 2009$ S. Karger AG, Basel

\section{Introduction}

Menopausal hormone therapy (HT) is a proven risk factor for the development of female breast cancer. The 'Women's Health Initiative' (WHI), a large randomized controlled trial, showed a significant effect of hormone therapy (estrogen plus progestin) on breast cancer incidence (relative risk, 1.26) [1]. The 'Million Women Study' (MWS), a cohort study with one million female participants, came to comparable results: risk for breast cancer was increased by $66 \%$ for current users of HT (estrogen plus progestin) [2]. Recently, a large population-based German case-control study revealed a significant increase ( 1.73 -fold) in the risk of breast cancer for current users of estrogen plus progestin HT [3]. These results emerged in 2003 concomitant with a sharp decline in HT prescription in many countries worldwide [4-8].

\section{KARGER}

Fax +4161306 1234

E-Mail karger@karger.ch

www.karger.com
(C) 2009 S. Karger AG, Basel

1015-2008/09/0762-0090\$26.00/0

Accessible online at:

www.karger.com/pat
Alexander Katalinic, $\mathrm{MD}, \mathrm{PhD}$, Institute for Cancer Epidemiology

University of Lübeck and Assoc. of Population-Based Cancer Registries in Germany Beckergrube 43-47, DE-23552 Lübeck (Germany)

Tel. +49 45179925 50, Fax +49 4517992551

E-Mail alexander.katalinic@krebsregister-sh.de 
Table 1. Incidence of breast cancer in Germany (pooled data based on cancer registries of the federal states)

\begin{tabular}{|c|c|c|c|c|}
\hline Federal state & $\begin{array}{l}\text { Female } \\
\text { population } \\
\text { millions }\end{array}$ & $\begin{array}{l}\text { Available } \\
\text { data }\end{array}$ & $\begin{array}{l}\text { population } \\
\text { included }\end{array}$ & $\begin{array}{l}\text { breast cancer cases } \\
\text { included }\end{array}$ \\
\hline Baden-Wuerttemberg & 5.6 & - & - & - \\
\hline Bavaria & 6.4 & 1998-2005 & no $^{\mathrm{a}}$ & - \\
\hline Brandenburg & 1.3 & 1998-2006 & yes & 13,500 \\
\hline Hamburg & 0.9 & 1996-2006 & yes & 11,200 \\
\hline Hesse & 3.1 & - & - & - \\
\hline Lower Saxony & 4.1 & $2000-2006$ & partly $^{\mathrm{c}}$ & 10,000 \\
\hline North Rhine-Westphalia & 9.3 & $1996-2006$ & partly & 15,400 \\
\hline Mecklenburg-West Pomerania & 0.9 & 1996-2006 & yes & 9,200 \\
\hline Schleswig-Holstein & 1.4 & 1998-2006 & yes & 21,300 \\
\hline Thuringia & 1.2 & 1996-2006 & yes & 13,100 \\
\hline Total & 42.0 & & 14.8 millions $(35 \%)$ & 163,100 \\
\hline
\end{tabular}

${ }^{\mathrm{a}}$ Low completeness in $1998-2002 .{ }^{\mathrm{b}}$ Completeness $<90 \% .{ }^{\mathrm{c}}$ District of Weser-Ems (female population: 1.3 million). ${ }^{\mathrm{d}}$ District of Muenster (female population: 1.3 million).

In 2006, Clarke et al. [4] firstly reported a 10\% decline in breast cancer incidence between 2001 and 2003. Shortly thereafter, Ravdin et al. [5] noted a sharp drop in breast cancer incidence from 2002 to 2003 in the United States (6.7\%), with the most pronounced decrease (11.8\%) occurring in women from 50 to 69 years of age. Subsequently, further publications from other countries confirmed the decline in breast cancer incidence $[6,9,10]$, but controversy persists [8, 11-19].

In Germany, a strong decline in HT was observed, with HT prescription almost halving in the age group from 50 to 69 years $[6,7]$. The decline in HT was associated with the WHI and MWS reports, the restriction of HT indication in the year 2003 by health authorities and the addition of HT drug information on the potential risk of HT to cause breast cancer. While the national estimate for Germany still assumes an increase in breast cancer incidence until 2004 [20], two German cancer registries reported a decline in breast cancer incidence for 2003-2005 [6, 21].

The aim of our collaborating study of German cancer registries was to collect and analyze recent and reliable data on HT and breast cancer incidence for individual federal states as well as entire Germany.

Hormone Therapy and Breast Cancer

\section{Patients and Methods}

The study was planned as a register-based survey using data from different data sources such as health insurance data (drug prescription data), cancer registries (breast cancer incidence) and the Federal Statistic Office (population data). They provided aggregated data (cases by 5-year age groups and year) from 1997 to 2005. The 16 federal states of Germany were studied both in total and separately for each federal state.

The present analysis is based on the prescription data of all finished drugs covered by the German Statutory Health Insurance and was provided by the AOK Research Institute. Hormone prescriptions are defined according to the classification of the Anatomical Therapeutic Chemical Classification System [22] as G03CA (estrogen), G03CX (tibolone) and G03FA/B (estrogen plus progestin), and were measured in defined daily doses (DDD; assumed average maintenance dose per day for a drug used for its main indication). Prescription data for Germany are accessible from 1997 to 2006, aggregated in 5-year age groups. At the federal state level, the total numbers of HT prescribed per year were available for the time period from 2001 to 2006. Therefore, agespecific analyses for HT were not possible at the state level and crude rates were used.

Breast cancer was defined according to the ICD-10 classification as C50 (invasive breast cancer) and restricted to women. Incidence data were collected from the German Federal State Population-Based Cancer Registries (table 1; see Acknowledgement for a list of participating cancer registries). Not all cancer registries 

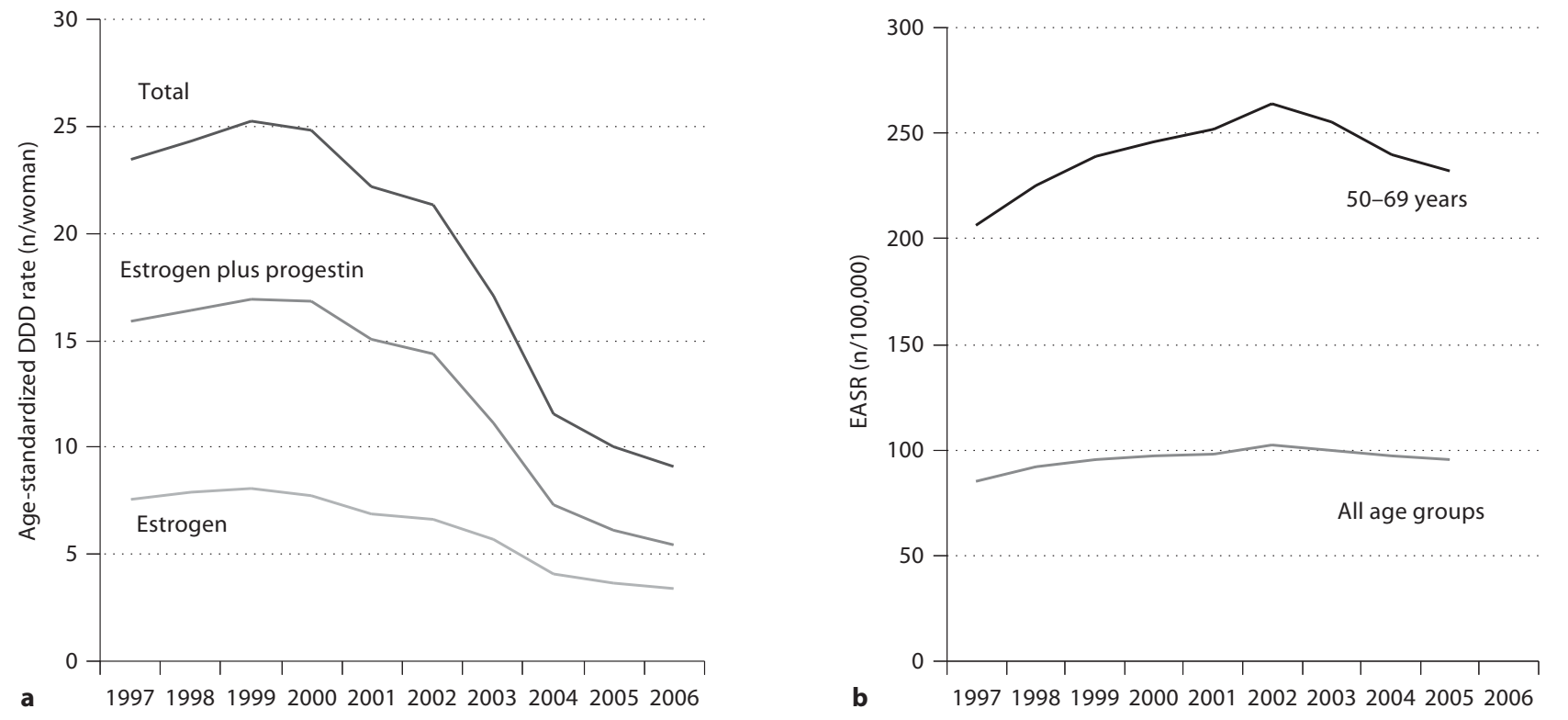

Fig. 1. Trends in hormone therapy (a) and breast cancer incidence (b) in Germany.

could provide data for the whole study period; for two states (Baden-Wuerttemberg and Hesse), data were not available due to ongoing installation of these registries. Incidence data were pooled to the 'German incidence pool', but Bavaria and Berlin had to be excluded because of incomplete data (registration $<90 \%$ of the expected cases) for the whole study period (table 1).

European age-standardized rates (EASR) were calculated. Incidence is given as rate per 100,000 women, and HT utilization as rate per woman. For the federal states, only crude rates could be calculated for HT prescription data. Trends were assessed by Joinpoint analysis and annual percentage change (APC) [23] using the Joinpoint Regression Program of the National Cancer Institute, Statistical Research and Applications Branch (version 3.3.1., April 2008). Where appropriate, $95 \%$ confidence intervals were calculated. Associations between HT and breast cancer incidence were assessed using Pearson's correlation coefficients.

\section{Results}

Data on hormone therapy were available for Germany (1997-2006) and for all its 16 federal states (2001-2006), representing a total of 7.7 billion DDD. About $80 \%$ of these doses were prescribed among the age group from 50 to 69 years. Twelve federal states contributed to the German breast cancer incidence pool, representing 35\% of the female German population with 163,100 breast cancer cases (table 1).

HT prescription started to decline in 1999 for estrogen plus progestin as well as for estrogen preparations; 2 years later, a parallel decline in breast cancer incidence was observed for the German incidence pool (fig. 1). Within 6 years (2001-2006), the decline in HT amounted to 59\% (22.1 vs. 9.1 DDD per woman), and breast cancer incidence was 6.8\% lower in 2005 than in 2002 (103 vs. 96 cases per 100,000 women) for all age groups and $12.8 \%$ lower (264 vs. 232 cases per 100,000 women) in the age group from 50 to 69 years. Age-specific trends in HT (hormones in total) and breast cancer incidence are shown in figure 2. HT rates were highest in the age groups from 50 to 59 and 60 to 69 years, with a steep decrease (-20\% APC) starting in 2001. While breast cancer incidence in the younger or older age groups showed no decline over the whole study period, a sharp fall with an APC of $-6.6 \%$ (from 50- to 59-year-old women) and $-2.9 \%$ (from 60 - to 69-year-old women) was noted for the time period from 2002 to 2005.

In 2001, HT rates in the German federal states ranged from 17.6 to 36.1 DDD per woman (Germany: 22.2 DDD per woman; table 2). Until 2006, declines were rather 


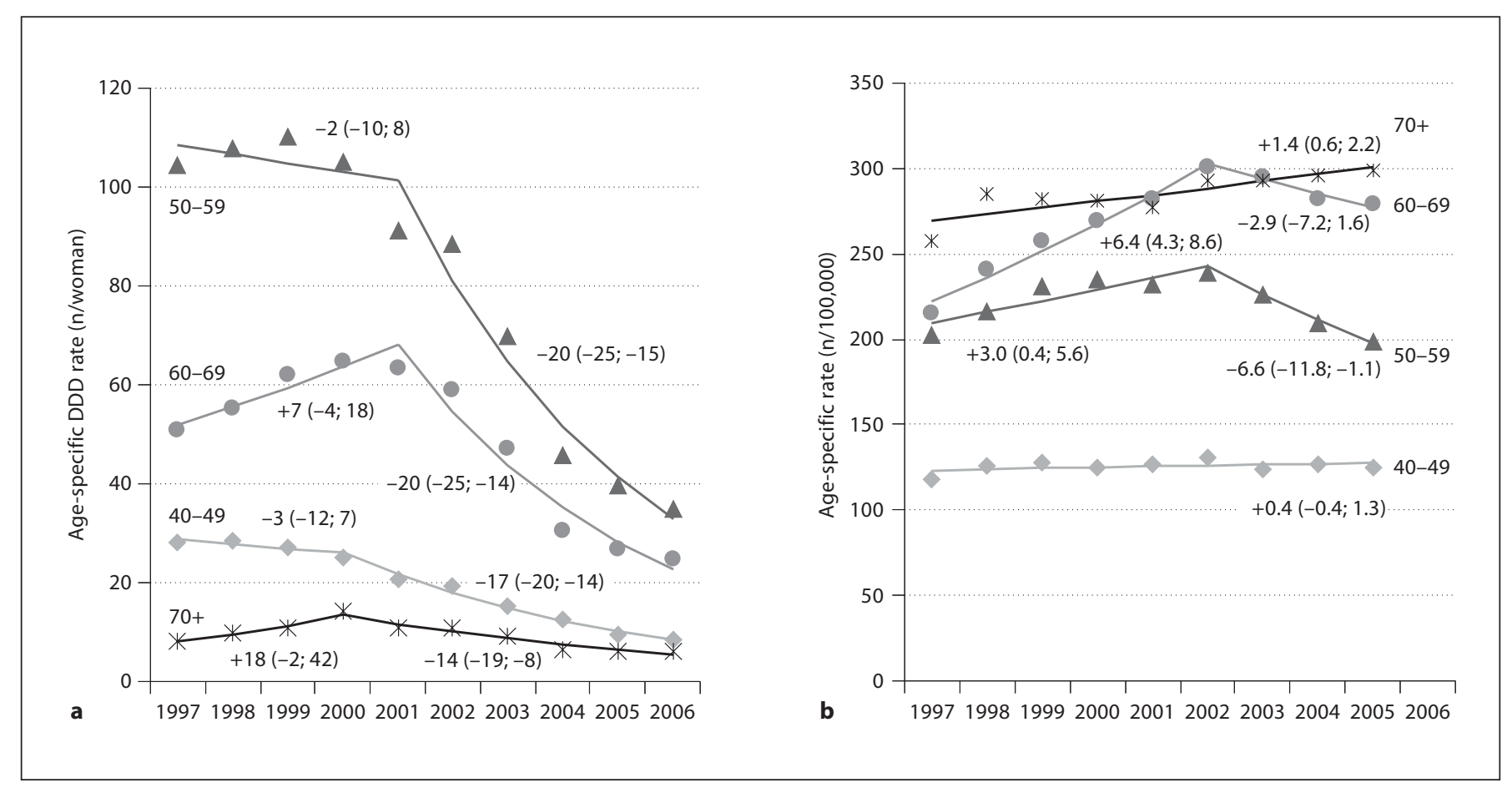

Fig. 2. Age-specific trends in hormone therapy (total; a) and in breast cancer incidence (b) in Germany. Observed HT/breast cancer incidence rates (symbols), regression lines fitted by Joinpoint analyses and APC (numbers) with $95 \%$ confidence intervals (in brackets) are shown for the various age groups.

Table 2. Hormone therapy (total DDD rates per woman) and age-standardized breast cancer incidence (EASR/100,000) in Germany

\begin{tabular}{|c|c|c|c|c|c|c|c|c|c|c|c|c|}
\hline \multirow[t]{3}{*}{ Federal state } & \multicolumn{4}{|c|}{ Hormone therapy (total) } & \multicolumn{8}{|c|}{ Breast cancer incidence } \\
\hline & \multicolumn{4}{|c|}{ all ages } & \multicolumn{4}{|c|}{ all ages } & \multicolumn{4}{|c|}{ age group 50-69 years } \\
\hline & 2001 & 2006 & APC, \% & $95 \% \mathrm{CI}$ & 2002 & 2005 & APC, $\%$ & $95 \%$ CI & 2002 & 2005 & APC, \% & $95 \%$ CI \\
\hline Brandenburg (1) & 18.8 & 6.8 & -20.6 & $-26.4 ;-14.3$ & 92 & 87 & -1.5 & $-4.5 ; 1.7$ & 231 & 198 & -3.9 & $-12.8 ; 5.8$ \\
\hline Bremen (2) & 36.1 & 12.3 & -22.0 & $-29.3 ;-14.0$ & 144 & 107 & -10.1 & $-19.1 ;-0.1$ & 417 & 279 & -13.6 & $-24.8 ;-0.6$ \\
\hline Hamburg (3) & 34.1 & 12.4 & -20.4 & $-26.3 ;-14.2$ & 122 & 102 & -5.8 & $-10.7 ;-0.6$ & 341 & 262 & -8.4 & $-15.2 ;-1.0$ \\
\hline Mecklenburg-West & & & & & & & & & & & & \\
\hline $\begin{array}{c}\text { Pomerania (4) } \\
\text { Lower Saxony-Weser- }\end{array}$ & 19.0 & 7.7 & -18.6 & $-25.1 ;-11.6$ & 88 & 89 & 0.4 & $-1.9 ; 2.8$ & 217 & 211 & -0.3 & $-7.9 ; 7.8$ \\
\hline Ems (5) & 28.3 & 11.7 & -18.4 & $-24.6 ;-11.8$ & 111 & 112 & 0.2 & $-2.2 ; 2.5$ & 302 & 291 & -1.6 & $-4.9 ; 1.7$ \\
\hline $\begin{array}{l}\text { North Rhine-Westphalia- } \\
\text { Muenster (6) }\end{array}$ & 28.7 & 12.2 & -17.4 & $-22.4 ;-12.1$ & 118 & 95 & -7.0 & $-15.3 ; 2.2$ & 297 & 233 & -8.9 & $-21.4 ; 5.6$ \\
\hline Rhineland-Palatinate (7) & 26.6 & 11.7 & -16.9 & $-21.1 ;-12.4$ & 100 & 96 & -1.7 & $-3.8 ; 0.3$ & 268 & 233 & -4.8 & $-8.3 ;-1.2$ \\
\hline Saarland (8) & 29.2 & 13.1 & -16.9 & $-22.7 ;-10.6$ & 111 & 102 & -3.2 & $-9.0 ; 3.1$ & 274 & 251 & -3.9 & $-18.8 ; 13.7$ \\
\hline Saxony (9) & 17.6 & 6.8 & -19.6 & $-25.2 ;-13.6$ & 85 & 84 & -1.0 & $-3.8 ; 1.9$ & 208 & 198 & -3.4 & $-11.6 ; 5.6$ \\
\hline Saxony-Anhalt (10) & 18.3 & 7.0 & -19.6 & $-25.4 ;-13.4$ & 84 & 81 & -0.3 & $-3.4 ; 2.9$ & 208 & 188 & -1.6 & $-3.2 ; 0.1$ \\
\hline Schleswig-Holstein (11) & 29.6 & 11.3 & -19.4 & $-24.9 ;-13.5$ & 143 & 129 & -3.5 & $-3.7 ;-3.4$ & 374 & 320 & -5.7 & $-11.2 ; 0.2$ \\
\hline Thuringia (12) & 20.8 & 7.9 & -19.9 & $-25.0 ;-14.4$ & 86 & 86 & 0.1 & $-5.0 ; 5.5$ & 207 & 198 & -0.7 & $-8.8 ; 8.1$ \\
\hline Germany & 22.2 & 9.1 & -18.9 & $-23.6 ;-13.6$ & 103 & 96 & -2.5 & $-6.8 ; 2.0$ & 264 & 232 & -4.7 & $-8.7 ;-0.4$ \\
\hline
\end{tabular}

$\mathrm{CI}=$ Confidence interval. 

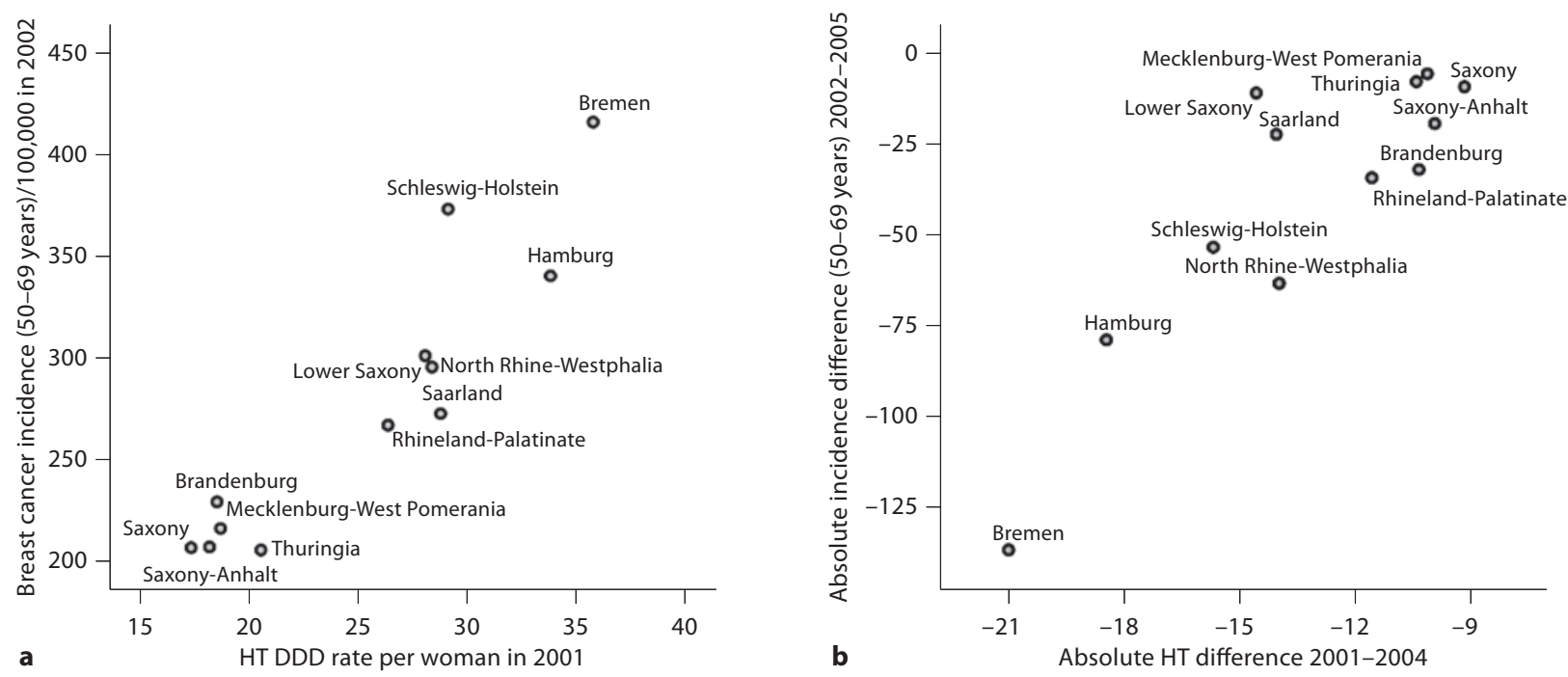

Fig. 3. Correlation between HT rate in 2001 and breast cancer incidence (age group 50-69 years) in 2002 (a) and between absolute difference in HT from 2001 to 2004 and absolute difference in incidence from 2002 to 2005 (age group 50-69 years; b). a $\mathrm{r}=0.92, \mathrm{p}<0.01$. $\mathbf{b} \mathrm{r}=0.87, \mathrm{p}<0.01$.

similar in all states (APC range: from $-16.9 \%$ to $-22.0 \%$, Germany: $-18.9 \%)$, but differences between the states persisted. Breast cancer incidence in 2002 varied between the federal states with age-standardized rates from 84 to 144 per 100,000 women and from 207 to 417 per 100,000 women in the age group from 50 to 69 years (table 2). The federal states with the highest hormone prescription rates in 2001 also had the highest incidence rates in 2002 (table 2, fig. 3a). Correlation coefficients (HT rate 2001 by incidence rate 2002) were $0.83(\mathrm{p}<0.01)$ and $0.92(\mathrm{p}<$ 0.01 ) in the age group from 50 to 69 years, respectively. For the German incidence pool, an annual decline in breast cancer incidence from 2002 to 2005 by $-2.5 \%$ for all ages and by $-4.7 \%$ for the age group from 50 to 69 years was observed. The absolute decline in breast cancer incidence was largest in the states with the highest absolute difference in HT rates with a correlation of 0.87 ( $\mathrm{p}<0.01$; fig. 3b).

\section{Discussion}

Our study shows a sharp decline in HT prescription for Germany beginning in 1999. Within 7 years, HT prescription was more than halved from 25.2 DDD per wom- an in 1999 to 9.1 DDD per woman in 2006 (69\% relative reduction). This result is consistent with recently published national and international data, where HT reductions up to $70 \%$ are reported $[4,5,7-9,24]$. The decline for estrogen plus progestin combinations was greater than for estrogen-only products (68 vs. $58 \%$ ), which is comparable to the corresponding 68 and $36 \%$ relative reduction reported by Clarke et al. [4] and to the findings of Kerlikowske et al. [9] (corresponding APC -34\% and $-7 \%)$. The observed HT trends were comparable for different age groups (APC range: from -14 to $-20 \%$ ) and for the German federal states (APC range: from -17 to $-22 \%$ ), the latter being somewhat surprising, because the federal states started from very different HT levels, ranging from a crude rate of 17.6-36.1 DDD per woman in the year 2001. An interesting geographical pattern was found, with lowest HT prescription rates in the East German states (table 2; states 1, 4, 9, 10 and 12, representing the former German Democratic Republic) and highest rates in the North German states (table 2; states 2, 3 and 11). It was assumed that states with high HT rates in the preWHI era (before 2003) would show a more pronounced fall in HT than states already showing a low HT rate, but this could not be confirmed, and as a result HT rates still differed by a factor of 2 across the federal states in the year 
2006. But even if the relative reduction in HT was almost equal in the single states, it has to be taken into account that the absolute reduction in HT was largest in the states with highest HT levels in the pre-WHI era. For example an absolute reduction of 23.8 DDD per woman (20012006) was observed in Bremen (relative reduction 22.0\%) compared to a reduction of only $10.8 \mathrm{DDD}$ per woman in Saxonia (relative reduction 19.6\%; table 2). This has to be considered for the further assessment of breast cancer incidence trends in the different federal states. The absolute HT reduction correlates with the population-based HT exposure and this might play an important role for the trends in breast cancer incidence in the federal states.

Also, breast cancer incidence in Germany varies distinctly between the federal states in the pre-WHI era and shows an almost identical geographical pattern for HT prescription. The East German states have significantly lower breast cancer incidence rates (EASR 2002: 84$92 / 100,000)$ compared to the region of West Germany (EASR 2002: 100-144/100,000), whereas the North German states show the highest breast cancer incidence (EASR 2002: 122-144/100,000). In 2002, breast cancer incidence started to decline in Germany. From 2002 to 2005, the age-standardized breast cancer incidence rate decreased by about $6.8 \%$, whereas the age group from 50 to 69 years showed a significantly larger decline (12.8\%). As mentioned in the Introduction, comparable declines in breast cancer incidence were seen worldwide. Clark et al. [4] noted a $11 \%$ decline in breast cancer incidence from 2001 to 2003 in a US health insurance population, and Ravdin et al. [5] reported a 11.8\% decline in the age group from 50 to 69 years for the US SEER (Surveillance, Epidemiology, and End Results) Program Registries from 2001 to 2004 . In a study by Kerlikowske et al. [9] based on $>600,000$ mammography screening examinations, incidence declined by 5\% per year (from 2001 to 2003). Breast cancer incidence ( $>40$ years) decreased by $4.4 \%$ per year in San Francisco Bay in 2001-2004, as reported by Keegan et al. [24], being almost similar to Germany (APC 4.7\% in the age group from 50 to 69 years). Taking a closer look at the 10-year age groups, the largest decrease in incidence was noted in women aged $50-59$ years $(-17.6 \%$ from 2002 to 2005). Jemal et al. [25] found the highest percentage decreases in women aged 55-64 years (10.614.3\%) from 2002 to 2003 in the SEER Cancer Registry.

The geographical patterns in HT prescription and breast cancer incidence are almost the same in Germany. Furthermore, parallel trends for HT and breast cancer incidence are evident, with a delay of $\sim 2$ years. Assessing the association of HT prescription and incidence rates reveals a high correlation. In the federal states, the correlation between HT rate (2001) and breast cancer incidence (2002) is high (fig. 3a; $r=0.92, p<0.01$ ). Federal states with the largest HT drop showed the largest decline in breast cancer incidence. Reduced HT exposure is highly correlated with the absolute reduction in incidence (fig. $3 \mathrm{~b} ; \mathrm{r}=0.87, \mathrm{p}<0.01$ ). These results support the assumption of a causal relationship between HT prescription and the risk of breast cancer, being the subject of discussion in several published reports $[4-6,9,21,26]$.

A causal relationship between declining HT prescription and decreasing breast cancer incidence can be discussed only after taking other factors into account that could have possibly also caused a fall in breast cancer incidence. Potential explanations for a lower breast cancer incidence could be a reduction in mammography screening, the end of a screening prevalence round or even declining completeness in cancer registration. These points were intensively discussed regarding the observed decline in international breast cancer incidence data $[5,19$, $26,27]$. However, none of these factors could plausibly explain the observed decline in breast cancer incidence. This might also be valid for our study in German women. Systematic mammography screening was started in two of our study regions (Bremen and Lower Saxony-Weser Ems) in 2003; in the other regions, screening commenced in 2005 and has not been finished yet. In fact, in Germany, mammography screening should rather lead to an increase than to a decrease in incidence (especially in the 50 - to 69-year age group). The national incidence estimates for Germany show a continuous rise in completeness in cancer registration for the German states [20]. Ongoing improved cancer registration and rising breast cancer incidence in women $<50$ and $>70$ years (fig. $2 \mathrm{~b}$ ) render incomplete cancer registration as a cause of a decline in breast cancer incidence in Germany rather improbable.

Due to the design of our study (observational registerbased study), the study does not have the power to prove a causal relationship between HT and breast cancer incidence, but the results represent another piece of the puzzle as Berry and Ravdin [27] mention in their editorial 'in observational studies causation could be interfered but not directly proven'. However, after discussing possible confounders, they also concluded that HT would be the only known factor to explain the recent drop in breast cancer incidence, in agreement with our results, since HT is still the only factor known to cause a drop in breast cancer incidence in Germany. 
Assuming a causal relationship between $\mathrm{HT}$ and breast cancer - and this assumption was proven by WHI and MWS trials - the observed drop in breast cancer incidence had to be expected following the reduction in the causal agent (HT) [18]. An interesting aspect of our results is the fact that the regional HT and incidence patterns in the era before the HT decline showed a high correlation. It can be assumed that these differences in incidence are also caused by differences in HT prescription in the last decades. This hypothesis is also pushed forward by Krieger [26] in her latest review on HT and breast cancer. Interestingly, the regional differences in HT prescription as well as in breast cancer incidence seem to persist. This point should be borne in mind during future public health discussions in Germany. Persisting HT differences might lead to continuing differences in breast cancer incidence.

\section{Limitations and Strengths of Our Study}

We have already discussed that proof of a causal relationship between HT and the risk of breast cancer is not possible using our study design. We also cannot rule out that screening effects (opportunistic screening might also be present in Germany) could play a role, but the direction of this possible source of bias is open. On the other hand, our analyses of breast cancer incidence are based on a huge population (15 million women) studied over a 10 -year period, and we investigated most reliable HT data for Germany based on the statutory health insurance data.

\section{Conclusion}

Our analyses strengthen the results of previous international studies and confirm a possible association between breast cancer incidence and HT in Germany. Overall a causal relationship between the risk of breast cancer and HT seems to be very likely. Even after the 'big HT drop' in Germany, the relevant differences in HT prescription as well as in breast cancer incidence persist between the federal states. These results should be discussed in a public health context.

\section{Acknowledgments}

Special thanks go to all persons who made this work possible by providing this valuable data: M. Meyer (Population-Based Cancer Registry of Bavaria), A. Eberle (Bremen Cancer Registry), S. Hentschel (Hamburg Cancer Registry), K. Kraywinkel (Cancer Registry of North Rhine-Westphalia), J. Kieschke (PopulationBased Cancer Registry of Lower Saxony), K. Emrich (Cancer Registry of Rhineland-Palatinate), C. Stegmaier (Population-Based Cancer Registry of Saarland), R. Stabenow (Common Cancer Registry of the Federal States of Berlin, Brandenburg, Mecklenburg-West Pomerania, Saxony-Anhalt, Saxony and Thuringia) and H. Schröder (AOK Research Institute).

\section{References}

1 Rossouw JE, Anderson GL, Prentice RL, LaCroix AZ, Kooperberg C, Stefanick ML, Jackson RD, Beresford SA, Howard BV, Johnson KC, Kotchen JM, Ockene J: Risks and benefits of estrogen plus progestin in healthy postmenopausal women: principal results from the Women's Health Initiative randomized controlled trial. JAMA 2002; 288:321-333.

2 Collaborators MWS: Breast cancer and hormone-replacement therapy in the million women study. Lancet 2003;362:419-427.

3 Flesch-Janys D, Slanger T, Mutschelknauss E, Kropp S, Obi N, Vettorazzi E, Braendle W, Bastert G, Hentschel S, Berger J, ChangClaude J: Risk of different histological types of postmenopausal breast cancer by type and regimen of menopausal hormone therapy. Int J Cancer 2008;123:933-941.
4 Clarke CA, Glaser SL, Uratsu CS, Selby JV, Kushi LH, Herrinton LJ: Recent declines in hormone therapy utilization and breast cancer incidence: clinical and population-based evidence. J Clin Oncol 2006;24:e49-e50.

5 Ravdin PM, Cronin KA, Howlader N, Berg CD, Chlebowski RT, Feuer EJ, Edwards BK, Berry DA: The decrease in breast-cancer incidence in 2003 in the United States. N Engl J Med 2007;356:1670-1674.

6 Katalinic A, Rawal R: Decline in breast cancer incidence after decrease in utilisation of hormone replacement therapy. Breast Cancer Res Treat 2008;107:427-430.

7 Heitmann C, Janhsen K, Glaeske G: The influence of published studies and position papers on the prescription of peri- and postmenopausal hormone therapy (in German). Gesundheitswesen 2007;69:379-384.
8 Zahl PH, Maehlen J: A decline in breast-cancer incidence. N Engl J Med 2007;357:510511; author reply 513.

9 Kerlikowske K, Miglioretti DL, Buist DS, Walker R, Carney PA: Declines in invasive breast cancer and use of postmenopausal hormone therapy in a screening mammography population. J Natl Cancer Inst 2007; 99:1335-1339.

10 Glass AG, Lacey JV Jr, Carreon JD, Hoover RN: Breast cancer incidence, 1980-2006: combined roles of menopausal hormone therapy, screening mammography, and estrogen receptor status. J Natl Cancer Inst 2007;99:1152-1161.

11 Bluming AZ: A decline in breast-cancer incidence. N Engl J Med 2007;357:509; author reply 513 
12 Cady B, Chung MA, Michaelson JS: A decline in breast-cancer incidence. $\mathrm{N}$ Engl J Med 2007;357:511; author reply 513 .

13 Elfenbein GJ: A decline in breast-cancer in cidence. N Engl J Med 2007;357:509; author reply 513.

14 Kliewer EV, Demers AA, Nugent ZJ: A decline in breast-cancer incidence. $\mathrm{N}$ Engl J Med 2007;357:509-510; author reply 513.

15 Robbins AS, Clarke CA: A decline in breastcancer incidence. N Engl J Med 2007;357: 511-512; author reply 513.

16 Signorello LB, Tarone RE: A decline in breast-cancer incidence. N Engl J Med 2007; 357:512-513; author reply 513 .

17 MacMahon B, Cole P: Is the incidence of breast cancer declining? Epidemiology 2008; 19:268-269.
18 Colditz GA: Decline in breast cancer incidence due to removal of promoter: combination estrogen plus progestin. Breast Cancer Res 2007;9:108-110.

19 Stang A: Decline in hormone replacement prescription and fall in breast cancer incidence - an epidemiological discourse. Dtsch Arztebl Int 2008;105:303-309.

20 Cancer in Germany 2003-2004. Incidence and Trends, ed 6. Berlin, Robert Koch Institute and Association of Population-Based Cancer Registries in Germany, 2008.

21 Katalinic A, Stegmaier C, Rawal R, Waldmann A: Less hormone replacement therapy, less breast cancer in Germany (in German)? Geburtshilfe Frauenheilkd 2007;67:12171222.

22 WHO Collaborating Centre for Drug Statistics Methodology. ATC/DDD index, 2008.

23 Kim HJ, Fay MP, Feuer EJ, Midthune DN: Permutation tests for joinpoint regression with applications to cancer rates. Stat Med 2000;19:335-351.
24 Keegan TH, Chang ET, John EM, Horn-Ross PL, Wrensch MR, Glaser SL, Clarke CA: Recent changes in breast cancer incidence and risk factor prevalence in San Francisco Bay area and California women: 1988 to 2004 . Breast Cancer Res 2007;9:R62-R73.

25 Jemal A, Ward E, Thun MJ: Recent trends in breast cancer incidence rates by age and tumor characteristics among U.S. Women. Breast Cancer Res 2007;9:R28.

26 Krieger N: Hormone therapy and the rise and perhaps fall of US breast cancer incidence rates: critical reflections. Int J Epidemiol 2008;37:627-637.

27 Berry DA, Ravdin PM: Breast cancer trends: a marriage between clinical trial evidence and epidemiology. J Natl Cancer Inst 2007; 99:1139-1141. 